ask him to expand his upper chest, not necessarily by
respiration, but by elevation of the stzpefior ribs by a musculareffort, at the same time slightly drawing in the day, the two first to be focused in the face with the abdominal wall. We now introduce the smallest mirror : mouth closed, and the attack to break upon the lips abdominal wal. Went to sing "A," pronounced as in law as much as possible on opening the mouth. At the end
or maw. With this position of the larynx and muscular of seven days the chords, instead of presenting an ellippoise we observe two things: First, the epiglottis does t tical appearane, were straight, and the nodule was
not assume its most vertical aspect, not inclining as so far rotated upward on either chord that it did not not assume its most vertical aspect, not inclining as : so far rotated upward on either chord that it did not near the perpendicular, and the soft palate anu uvula
do not spring upward and back ward to make the parent in every respect is the tone produced by the chords, ent in every respect is the tone produced by the chords,
which may be assumed to vibrate longitudinally, but
never touching each other in the middle portion, even never touching each other in the middle portion, even
in making the initial attack. The chords appear narrower, tenser, lower anteriorly, equidistant from each
other, more liomogeneous and whiter in color. become the basis of criticism in distinguishing the correct and eliminating incorrect methods, on the one to the laryngologist in correcting jet thelogical condi-
tions, the result of bad training. the proper appreciation of these opposite conditions and their effect on
the quality of tone inmmediately calls our attention to the entire theory of musical education has changed in France, the explanation of this change being that there bearing upon the production of tone and a better un-
derstanding of the physiology of the larynx, by reason of the advances made in laryngoscopy. and sympathy in the voice at the expense of brilliancy of execution. The same judgment should be exercised
in the training of an individual who proposes to make singing his or her art as should be employed in advisrich in color, in which he may give expression to his
imaginative genius, rather than to the sterner facsimile of portraiture.

How many singers we hear whose technique and
briliant our admiration and amazement, but who are absolute ly unable to put any sympathy whatsoever into the
simplest ballad! We should study color harmonies in music in the same way that they must be studied
in painting. There is no rule for the palpitating sunin painting. There is no rule for the palpitating sun-
light effects and prismatic play of colors in the school of Claude Monet; it is certainly a subtile feeling which is given by an ingenious mingling of pure spectrum
colors. In the human voice that added coloring of tone which appeals to the heart as well as to the ear of the
listener must be brought about by the employment listener must be brought about by the employment
of those harmonies which are added to the original tone by intervibrations within the accessory cavities
of the nasal passages. To sing dans le masque, as the French say, is to give this added richness to the initial ate and uvula to be lowered in the production of tone Likewise to make the purest initial tone from the
chords, we must get, the utmost possible tension, which nlay only be arrived at when the thy reoid is depress-
ed, for, in proportion as the thyreoid is elevated, the chords tend to assume the base of a right angle triansides this enter into the question of greatest possible tension, one of the most important of which is that
the trachea be drawn down to assume the position that it takes when the apices of the lungs are filled One of the greatest singers the

told me that the reason that he adopted a fixed high chest was that he had found, after the removal of a papilloma from one of his chords, that the only way ing was by the maintenance of the so called high chest
respiration. This is easily explained by the fact that. in this position, the upper ribs remaining fixed, the apices of wall, expanded to their fullest extent, the chords being
kept in their state of greatest possible tension. In this position the breathing becomes entirely inferior costal
and diaphragmatic. The position of the thorax, as and diaphragmatic. The position of the thorax, as indicated above, permits the lungs to expand to their
fullest extent, thus adding a secondary resonance to
the voice from below-a sort of complementary timbre, the fixed upper thorax allowing of the least possible change of color during tone production. fortification which gives the enormous carrying power
to tones produced by this method. For a number of to tones produced by this method. For a number of
years before I made a special study and estimated the
great significance of these factors in singing, I deluged the throats of singers with sedative and astringent sprays when theirchords appeareti congested and swolhad never previously recognized as being due entirely to singing with an improperly poised larynx.

I may cite several cases to show you the difference,
from a medical standpoint, in the treatment of the singer's throat, where I now substitute respiratory and tone exercise for the amelioration of conditions that
I have always been taught were only to be cured by rest and the diligent use of drugs. The cases I cite
are typical of a class of singers that I have treated with equally good results since I have nade a particular
study of the peculiar value of the proper tone production in the human voice.
CASE I.-The first day of January last I was consul ed by Miss F., aged twenty-three years. who had had a contralto voice of large power which she had employa prolonged concert tour with a well-known orchestra, a slight nodule in the middle of either band; she commedium register had no power in it whatsoever. She had been told by two of the best authorities on the throat that she must not sing a note for a year, and
must have her chords painted with astringent solution and tone up her general health. Upon testing her
voice, I remarked an extremely breathy tone and clavoice, I remarked an extremely breathy tone and c
vicular respiration.
In accordance with the principles which $I$ have tempted to demonstrate, I forbade her speaking a sin-
gle word for a week, but placed her at once upon the
so-called inferior costal respiration, maintainins a high gle word for a week, but placed her at once upon the producing the disease, still sunlight will destroy them
so-called inferior costal respiration, maintaining a high he of a few hours. Nature has thus put a
chest, and givit to their destructibility, and has also given to
lime directions to take a medium "g," healthy animal tissue, in the great majority of cases, treatment the power of expelling or annihilating the germ, else
tubercular affections would be far more prevalent than at present

The importance of this germ theory of disease as apProf. Koch is due all credit, for the discovery
distinctively his. It is now classified by our best sanitarians as a " preventable disease," and in the same category as diphtheria, sinallpox, scarlet fever.
etc. The importance of this discovery is emphasized fone. At the end of the week this young lady, who etc. The importance of this discovery is emphasized
considered her voice hopelessly destroyed, having ac- by the fact that about thirteen deaths out of every uired a new method of respiration, sang in a concert Stie has since sung regularly in church, in many oratoios during the winter, and is at present singing three
imes a week in grand opera, learning new roles con tinually, apparently perfectly restored. She tells me CASE II.-Miss P. H. consulted me on March 2 in reat distress. She was obliged to sing in a comic
opera on that evening or close the theater. Examination showed inflamed and bulged chords, with great ossible, but the high notes obtained with great effort. to maintain tension, and at the end of an hour' work with tension exercises and inferior costal br
ng the cords responded and she sang with ease.
CASE III.-Miss H. B. consulted me in May, hav

ost her position as prima donna by reason of loss of d the nodules of attrition, the result of the employ mis case a week's work caused the nodules to disappear. She adopted a proper laryngeal poise and again
par Observation. - In this class of cases rest causes a re-
axation of the chords and singing becomes impossible axation of the chords and singing becomes impossible for some time, whereas constant work, with tension
of the chords and non-approximation of the same, gives CASE IV.-Fraulein K. consulted me in the spring. Her chords appeared swollen and the membrane was cancel her engagements and return to New York for heatment. I recognized the familiar picture and sent

With many cases like these which I might cite, may
ta With many cases like these which I might cite, may
I not be excused in my assumption in calling attention to what I consider the most inportant ground prinei
ple of the singer's art - namely, the proper employment and the proper use of the intrinsic muscles of the accessory cavities of the face, which lend so much color to the tone, removing entirely from the chords the

To rehearse briefly the deductions which I have at
empted to draw from my argument. I maintain that tempted to draw from my argument, I maintain that diaphragmatic, faithfully main taining the elevation of mportance is the depression of the thyreoid cartilage reoid nuscles and the pulling down of the trachea, by increasing the capacity of the upper lobes of the lungs
-anatonically speaking, a pose causing the thyreo-anatonically speaking. a pose causing the thyreois removed entirely from the chords. Lower the uvula and soft palate, that the sound waves may obtain their into the nasal cavities from behind. Let us not fal
into the error that the reof of the mouth alone is the sounding board of the singing voice, for without that sory cavities, we may sing, but the singing is at the expense of the chords, and the life of the voice is neces-
sarily shortened.
If I have said enough to arouse a new interest in what I consider a most necessary accessory to laryngology, I shall feel amply repaid for my endeavors

\section{BOVINE TUBERCULOSIS.}

By Henry G. Wolcotr, New York State Commis Iv a recent letter to the editor of the Orange Coun-
Farmer, State Commissioner Wolcott gives the most recent information on the above subject, as fol-
ows:
I have read with much interest in your issue of March 8 the statements relative to bovine turberculosis, and Since comparatively little is generally known upon
the subject, I think it may not be devoid of interest to our readers to learn some of the facts which have your readers to learn some of the facts which have
induced such efforts, and while in thus addressing rou
I shall have, necessarily, to indulge in the "scientific," believe that all information upon this most import Bnt subject is worthy of attention.
Bovine tuberculosis is practically the equivalent of the like disease in humans, be it known as pulmonar names, as scrofuletic affections, or under many other
namiar to the medical profession, varving in name with the symptoms or part affected. In all such osis." a microscopic vegetable parasite, in shape like a
bite of very fine thread, and when viewed through a a sixteenth of an inch in length. These germs increase by segmentation, that is, they break up, and each

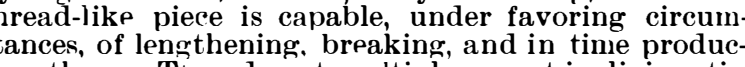
ing others. They do not multiply except in living tis sue or in animal products, such as blood, serum, bee
broth, or the like; and while they may live for years producing the disease, still sunlight will destroy them ndred are caused by some form of this disease. covery marks an era in the nineteenth century. That ist in rattle, that cattle can communicate it to mem-
bers of the human race and to other cattle, is without
doubt. That it can be communicated from man to doubt. That it can be communicated from man to many cases is, hereditary, is also established; or, if the offspring of non-tuberculous its influence than are he offspring of non-tuberculous parents.
There are within the State of New York about a million and a half of milch cows, and about two and half milion of aninals whose annual dairy product ex-
ceeds $\$ 35,000,000$. The records of the State Board of
Health show that $3 \%$ per cent. of all cattle examined re tuberculous. Hence, looking at the question from flected. Considered from both the sanitary and pecuniary standpoints, how momentous a question this
proves itself to be. The cause of all this trouble, the bacilli tuberculosis ute solution of nitric acid has no effect upon them, while destroying other germs. Again, a dye known as or no effect upon other bacilli. If, then, upon a micro-
scopical examination, we find them in diseased tissue,
inoculate heaithy tissue with them, again finding the specific germ, and carry this operation on through seventy different series of animal cultures, taking proper antiseptic precautions in every case, and have the sevnature, still finding the sane specific bacilli, we may Koch and other observers, and the results as stated esablished and acknowledged as facts. The only animals, tablished and acknowledged as facts. The only animals,
so far as known, upon which such inoculations have no
effect are rats and mice. Guinea pios and rabbits are particularly susceptible to its infuence, and upon
hem the great majority of experiments have been The contamination from the human to the human or to the hovine is presumably by the sputa, which nd when a suitable lodgment is found in susceptible issue, either in the respiratory or alimentary tracts, gernination and increase nay result, producing a tu-
bercular affection, specifically named in accordance with the orgals affected. The communication from
the bovine to the adult bovine is by the sputa mainly, the bovine to the adult bovine is by the sputa mainly,
the wn habits of cows licking each other, feeding from the same troughs, etc.. being familiar exam-
ples. Calves frequently take it in their mother's milk. It is mainly comnunic through the milk.
While it may be

While it may be communicated through tuberculous meat, the fact that meat is usually cooked and that a the bacilli and prevent much danger on this score. A tuberculous cow may or may not have tuberculous
tuilk. depending in measure upon the part affected and the extent to which the disease has developed the milk is generally tuberculous. The certainty that time of observation will, during her life, limited at the best to a few months or years, prove a source of contagion to all remaining healthy members of the herd,
the fact that her milk may at any time become tuberculous, and the further fact of her progeny being probably tuberculous, would warrant her destruction. A milk-producing cows. It is a curious fact that butter when made by either the separator or ordinary methods seldom contains tubercular germs even when made
from milk known to be tuberculous. The reason for this doubtless is that the specific bacilli referred to are portion. This fact enables the skilled pathologist to portion. This fact enables the skilled pathologist to
the more readily find the bacilli by using a centrifugal
apparatus which concentrates them in a certain portion of the fluid under examination.
About two years ago the State Board of Healtl, re About two years ago ant bearing of the facts above
mentiong the inmportant, commenced its crusade of enlightenment. It takes to itself no little credit that among all the States of the Union it was the first to establish a deand most authentic information upon the subject ness of theoretical deductions, based upon such facts,
ould be practicatly provert or disproved. Pennsylvanow following in our lead, and the Bureau of Animal The use of Koch's tuberculine or lymph as a diagnostic agent in cases of suspected tuberculosis has vastly increased the possibilities of eradicating the dis-
ease. Many fallacious notions exist as to this tuber-
culine and its effects upon the animal inoculated. In the hands of a skilled, conscientious and experienced
specialist, it can effect no possible injury. It will not
cause the disease, nor will it increase the disease in
affected animals. In unskillful hands it is likely to affected animals. In unskillful hands it is likely to give results that are not borne out by the post mortem tious and experienced specialist the information it There are as yet certain attendant facts and circum-
stances connected with the correct readings of the in
dications it gives that make the information obtained by physical examinations important in doubtful cases 
and while the State Board of Health uses its best en-
deavors to obtain inspectors who shall fulfill all the redeavors to obtain inspectors who shall fulfill all the renual appropriation of ten thousand dollars will not permit of its paying salaries to its inspectors commen-
surate with the skill and experience demanded. The faulty diagnosis, as evidenced by the post mortem exaninations amounting thus far to about three percent. of the animals slaughtered, is due not to errors in the
principle employed, but to errors in the method, carelessness or ignorance on the part of the user of such principles, and in nowise affects the efficiency of the tuberculine test as a diagnostic agent.

The tuberculine is imported into this country, and although the department in Washington has the formula for its production, still the febrile reaction of
the two brands differs. Just what or how the tuberculine is produced is not generally known. It is gen-
con erally believed to be a ptomaine of the bacilli tubercu losis in pure glycerine.

head will suppose that the owner of a herd of say forty two or three animals past year, unaccountably lost coats, feverish eyes, are thin and low spirited. The milk supply may be normal or even increased. Two o three have a cough, and to sum it up the owner would among cattle and writes to the State Board of Health at Albany, asking that an examination be made of his cattle at the expense of the State. After waiting several months (we have over fifty applications on file and unattended to), he receives notice that on a certain day the inspector will make an examination. "He is than even that the purchased animal came from a herd known to be tuberculous. The cattle are then numbered, examined physically with much care, and the results entered.

If the facts warrant it, the cattle are thereupon tagged
and quarantined. The owner is directed to reenoved cows within two weeks of calving, and all cows bulling unless the physical exanination clearly shows them to culine test is apt to give undue reactions in such case and to similarly feed and water his entire remaining
herd. One hour after feeding the temperatures of all herd. One hour after feeding the temperatures of al ity of whose readings under similar changes of temwill take temperatures five hours thereafter and again at ten hours. During the interim the cattle are to be neither fed nor watered.
of all results so obtained.

of all results so obtained.
He will then order the cattle well fed and watered He will then order the cattle well fed and watered
and will proceed to inoculate the animals with be injected, based upon the weight of the animal to
be tested. About seven hours thereafter he will again commence taking temperatures and without permitting feeding or watering take eight temperatures at intervals of two hours each, after which the test
ceases and the animals may be fed and watered. Now conmences the real work of the inspector and board depends. The inspector will remember that board depends. The inspector will remember that twelve and $t$ wo at night than at midday, that free
watering may reduce the temperature one and a half watering may reduce the temperature one and a half
degrees, that a bull has two degrees higher temperadegrees, that a bull has two degrees higher tempera-
ture than a cow, and that chewing the cud is certain ture than a cow, and that chewing the cu

to run the mercury up at least one degree
It is trying work, and the tendency is to let the doubtfui cases remain under quarantine pending sub upon the omner, and should be, so far as possible,

upon the owner, and should be, so far as possible,
Depending upon the results of his study of the chart, he orders some freed from quarantine; some he coning cards from the ward in Albany. If the rise is spasmodic, resuming or approximating the normal as the tests continue, other things equal, the animal is
non-tuberculous. If there is a gradual and regular rise, reaching its maximum at the seventh or eighth test and showing an increase of upward of three degrees above the normal, the animal is almost received the cattle are killed under his direction and post mortem examinations made. The carcess is
buried usually in quicklime or removed to a phosphate factory.

It is believed by the board that it as a body cannot alone ever eradicate this disease. The subject is too subject before the people, and let the individual or the local boards in co-operation with the State board attend to the details. It is hopeful that the health departments of cities will appreciate the importance
of the subject and issue a quarantine against tuberculous milk. It hopes that in the near future a corps of specialists will be granted from our agricultura will be a prerequisite to the possibility of sale, and will be a prerequisite to the possibility of sale, and
that the ultimate result will be a material lessening
of the death rate and a demand for the animals and dairy products from the State of New York by reason of their known freedom from disease.

ROOSTING BUTTERFLIES

by JoHN T, Carrington.

Considering that more than half the span of life allotted by nature to the perfect state of butterflies is spent in sleep, it is of the first consequence that
the manner of roosting should be as far as possible protin the active and well able to save themselves sun is hot and their power of flight is strong, they are perfectly helpless in the dusk of evening, the night pick them up with our fingers and place them on our hands without the slightest show of movement on
the part of the insects. When in this condition of torpor or sleep induced by absence of sunlight, torpor or sleep induced by absence of sunlight, provided for the continuance of their species. There-
tore, we must conclude that the habit of roosting
adopted by each kind is most conducive to protection during the long hours of sleep. When we take the list of the European Rhopa-
locera and scan it deliberately through, it is only possible to come to one conclusion upon the know ledge possessed as to the manner of roosting of the
various butterflies. Indeed, we, in this country,
need not take the whole European list if we are in search of discovery into the resting habits of these insects. Very little is really known about the roost-
ng positions, from the protective point of view, of the majority of our British species. Most entomologists know how to hunt for several of our "blues," or
Lycænidæ. Various kinds are to be found so soon as



PIERIS RAPAE, ROOSTING ON PEA BLOSSOM.

the sun has set, resting upon the stems of grass; Some species invariably rest with the head of the in sect turned a way from the earth, looking skyward,
while other species always roost with the head looking downward. One wonders why nearly allied anderside of the wings, which is the only side visible
und adopt these unlike positions on the stems of grass. Some of the fritillaries (Argynnidæ) and Melitas
often affect the heads of flowers as the night resting place, though I fancy this is rather accidental than at night were "caught" in that position by the sun oing down while they were feeding off the honey in
the flowers, as so often seen with humble bees. We cannot find a large proportion of say Argynnis euph-
rosyne or Melitcea athalia out of the total population
of these species in any locality affected by them at est on the flower heads. Still it is not uncommon to find both species in that position on a dull morning
after a bright day. I have seen seventy of the latter kind on heads of thistle and other flowers in a Sussex. So, likewise, may we find the grizzly skipper Sussex. So, likewise, may we find the grizzly skipper
at rest, though chiefly on lower growing flower heads. Hesperia comma sits upon the smooth stems of young downs where it flies, and $H$. sylvanus has much the
same habit. Another of our skippers, Nisoniades ages, may be taken in sufficient abundance by search- explorers we may mention the Norwegian, Martin Eck

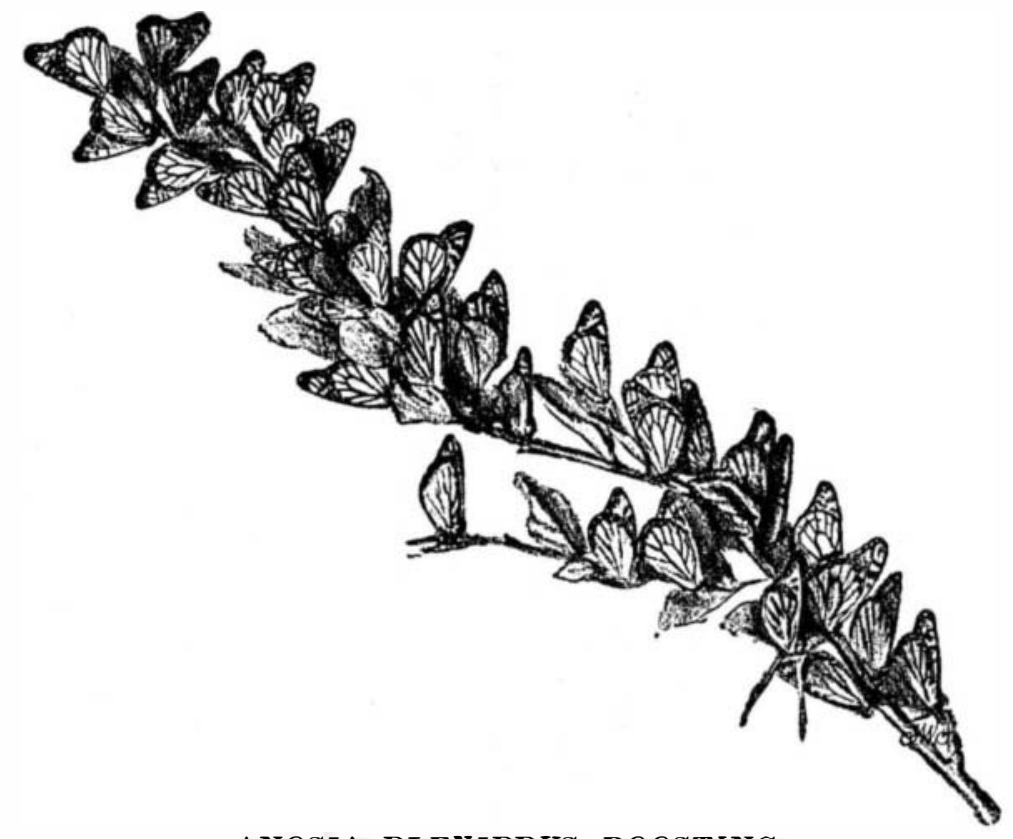

ANOSIA PLEXIPPUS, ROOSTING.

position quite unlike others of the group native to terested in Arctic expeditions, and has a theory that a these islands. It folds its wings under the body, like so called sledge boat, drawn by a number of dogs, noctuid moth. On one evening, on the Horsley
could go over the ice from Spitzenbergen to Franz
Josephsland, and from there over the North Pole to napweed for varieties of this dingy skipper butterfly

列 my entomological net, with the result that four addi- expedition, consisting of ten persons, started last sum-
ional butterfies were shaken off. The protective mer, in the sealing boat Falcon, for Whale Sound, in
mont position selected was so perfect that all my trained
the northern part of the western coast of Greenland,
where the expedition will winter. In the spring the the plant. I quote Mr. F. W. Frohawk's notes, taken when he herein reproduced from his drawing. "August 19,1885 , between 10 and $11 \mathrm{~A}$. M., dull day,
found Pieris rapoe, female, at rest on pea blossom, roll, a wealthy merchant of Lofoton, who is greatly in -

nd color. It remained motionless until noon on the and it flew away. The sinilarity between the unexAbout tnree years ago I was visiting a house wel ne recently grown branch had developed a few he ordinary green leaves. This branch being near Every evening for several days, about sunset to search out one of these half dozen white ivy leaves, of the creamy white leaf for the creamy white un seemed to be the same individual on each evening. flies at rest of some three dozen Plexippus butter from a photograph by Prof. C. F. Nachtrieb, of the of America, who lent the picture to Insect Life, the division of the United States Department of Agriculis larger than any species native to our islands, so an would have the appearance, when seen at a distance, of withered leaves attached to a dead branch. W reason, as apart from instinct, guides, the cannot fail to see how important for the preservation
of butterflies is the selection of suitable roosting places NANSEN'S EXPEDITION TO THE NORTH THE remarkably brisk rivalry that has lately de-
eloped in the field of polar exploration gives ground or the hope that during the next few years many Arclectric light and thephonograph-that lend their aid, most notable ones, as far as the expeditions themselves from many different directions, are the following : The hopes to reach his goal from the island of New Siberia;
he North American expedition of Lieut. Peary. who will push to the north by way of Greenland; and the
expedition of the Englishman, Fred. Jackson. who ides these an Josephsland as the starting point. Beplil be sent out from America, for the purpose of exill be conducted by a German connected with the name, will go north United States, Robert Stein rinnell Land, because those who are supposed to now about such matters claim that the best route to where the expedition will winter. In the spring the expedition will start by the route followed by the for-
mer Peary expedition over the inland ice to Independence Bay-shown in the accompanying map-and when this point is reached, they will divide into groups,
one of which will be led north ward by Lieut. Peary,
while another will explore the unknown coast from Igas seen by Prof Nachtrieb. Being in color yellowish dossip the helpless period of sleeping. - Science f the North Polar regions will present quite a differmethods employed for conducting such expeditions to 